\title{
OTOLOGY
}

\section{Canal wall down approach for tympano-mastoid cholesteatoma: long-term results and prognostic factors}

\author{
La timpanoplastica aperta per il trattamento dei colesteatomi timpanomastoidei: \\ risultati a lungo termine e fattori prognostici
}

\author{
R. PARESCHI, D. LEPERA, R. NUCCI \\ Department of Otorhinolaryngology, Ospedale Nuovo di Legnano, Milan, Italy
}

\begin{abstract}
SUMMARY
The aim of this study is to analyse the long-term anatomical and functional outcomes and prognostic factors of the canal wall down (CWD) tympanoplasty for the treatment of tympano-mastoid cholesteatoma. A total of 895 patients treated for tympano-mastoid cholesteatoma with follow-up longer than 10 years were included. Recidivism (recurrent and residual) cholesteatoma rates and functional results were analysed. The rate of recidivism was 7.7\% (6.7\% persistence and 1\% recurrent disease). Recidivism was higher in paediatric patients (10.1\% versus $5.0 \%$ of adults). Pathological middle ear mucosa and pars tensa was associated with increased rates of recidivism. Postoperatively, air pure-tone-average (aPTA) $\leq 30 \mathrm{~dB}$ was achieved in $36.4 \%$ of patients. Of 895 patients, a revision CWD tympanoplasty for chronic otorrhoea was performed in 14 cases $(1.5 \%)$ with complete recovery in all cases. Nine of those patients had a recurrence of cholesteatoma and five had cavity problems related to granulation, de-epithelisation or recurrent infection. Paediatric patients and absence of stapes superstructure were associated with the worst auditory outcomes. Six-month results were always better than long-term results. A CWD approach was demonstrated to be effective, achieving the goals of cholesteatoma treatment.
\end{abstract}

KEY WORDS: Cholesteatoma • Chronic otitis media $(\mathrm{COM}) \bullet$ Canal Wall Down $(\mathrm{CWD}) \bullet$ Open mastoid cavity

\section{RIASSUNTO}

Lo scopo di questo studio è di analizzare i risultati anatomici e funzionali e i fattori prognostici a lungo termine della timpanoplastica aperta per il trattamento del colesteatoma timpano-mastoideo. Sono stati inclusi 895 pazienti consecutivi con un follow up superiore a 10 anni. Il tasso di recidiva complessivo è risultato $7,7 \%$ (6,7\% di persistenza e $1 \%$ di malattia ricorrente). Il tasso di recidiva è stato più elevato nei pazienti pediatrici (10,1\% rispetto al 5,0\% degli adulti). La presenza di mucosa dell'orecchio medio patologica e le alterazioni della pars tensa della membrana timpanica sono state correlate con un aumento dei tassi di recidiva. Al follow up a lungo termine, nel $36,4 \%$ dei pazienti è stata ottenuta una "pure tone average" sulla via aerea (aPTA) $\leq 30 \mathrm{~dB}$ e i risultati a sei mesi erano sempre migliori dei risultati a lungo termine. L'età pediatrica e l'assenza della sovrastruttura della staffa sono stati associati ad un peggioramento dei risultati uditivi. Una timpanoplastica aperta di revisione per otorrea cronica è stata eseguita in 14 pazienti (1,5\%) con un recupero completo in tutti $i$ casi. Nove di questi pazienti erano affetti da recidiva di colesteatoma mentre cinque pazienti hanno avuto problemi di cavità correlati a granulazioni, disepitelizzazione o infezione ricorrente. La tecnica aperta per il trattamento del colesteatoma timpano-mastoideo si è dimostrata essere efficace, raggiungendo gli obiettivi del trattamento del colesteatoma che includono l'asportazione del colesteatoma con un basso tasso di recidiva in termini sia del colesteatoma residuo che ricorrente, preservare o recuperare l'udito e creare un orecchio asciutto.

PAROLE CHIAVE: Colesteatoma $\bullet$ Otite media cronica $・$ Timpanoplastica aperta $\bullet$ Mastoidectomia aperta

\section{Introduction}

Cholesteatoma is a mass in the tympanic cavity and/or mastoid cavity, formed by keratinising squamous epithelium, subepithelial connective tissue and the progressive accumulation of keratin debris with or without a surrounding inflammatory reaction ${ }^{1}$. Surgery is the treatment of choice and its objectives are the complete removal of the disease, creation of a safe, dry, and disease-free ear, and preservation or restoration of hearing as far as possible $^{2}$. The surgical approaches are classically divided into open approaches (or canal wall down - CWD) and closed approaches (or canal wall up - CWU) ${ }^{34}$. There has been a lengthy debate on the merits of the CWU versus CWD technique as is the optimal surgical strategy ${ }^{5}$.

The aim of this study is to analyse the long-term anatomical and functional outcomes of CWD tympanoplasty 
for treatment of tympano-mastoid cholesteatoma in 895 patients with follow-up between 10 and 24 years, and to evaluate the prognostic factors that influence outcomes.

\section{Materials and methods}

The present study is a retrospective evaluation of patients treated for tympano-mastoid cholesteatoma at the Otorhinolaryngology Department of the Ospedale di Legnano (Milano, Italy) between January 1992 and March 2016. Patients with incomplete medical records and less than 10 years of follow-up were excluded. Patients with residual or recurrent cholesteatoma previously treated elsewhere were excluded. The presence and extent of the cholesteatoma and status of the tympanic membrane were assessed preoperatively by otomicroscopy and/or otoendoscopy, with radiological examinations (CT scan without enhancement), and a pure-tone and speech audiometry within 3 months before scheduled surgery. Patients affected by tympano-mastoid cholesteatoma were treated only with a CWD tympanoplasty, which was performed by the same surgeon (R.P.) with the same technique, thus avoiding selection biases.

After surgery, the patients were evaluated by otomicroscopy and audiometric examinations at the $1^{\text {st }}, 6^{\text {th }}$ and $12^{\text {th }}$ month in the first postoperative year and then every 1 or 2 years.

The incidence of recidivism, residual and recurrent cholesteatoma was obtained. The anatomical recidivism rate was evaluated according to the extent of cholesteatoma (with or without involvement of the tympanic cavity). Patients were divided into two groups according to the condition of the pars tensa and middle ear mucosa. Group A included patients with normal or slightly inflammatory middle ear mucosa, and normal or slightly retracted pars tensa. Group B included patients with hyperplastic polypoid, and/or keratinizing middle ear mucosa and perforated part tensa or with severe atelectasis. The anatomical results in terms of rates of recidivism, persistent and recurrent cholesteatoma were obtained and compared between the two groups.

The functional results were evaluated with the pure-tone average air conduction thresholds (aPTA) at 500, 1000, 2000 and $4000 \mathrm{~Hz}$ after 6 months and more than 10 years. Patients with postoperative aPTA $\leq 30 \mathrm{~dB}-\mathrm{HL}$ were considered to have serviceable hearing with no need for hearing aids. The variables evaluated were: length of followup, clinical condition of the middle ear mucosa and pars tensa (group A and B as previously described) and the presence of the stapes superstructure. Functional and anatomical results were also evaluated according to the age ( $<18$ years; $\geq 18$ years) .

All data were collected and processed using a commercially available software package (SPSS for Windows, version 19, 2010; SPSS, Chicago, IL, USA). Statistical analysis used Chi-squared or Fisher's tests (p values $<0.05$ were considered statistically significant).

\section{Surgical technique}

Local or general anaesthesia was used according to the general status and preferences of patients. The temporalis fascia was harvested as grafting material using a postauricular skin incision $1 \mathrm{~cm}$ behind the postauricular sulcus. The anteriorly based postauricular periosteal flap was elevated, until the mastoid process was adequately exposed. The posterior skin of the external auditory canal (EAC) was progressively detached from the bone, from 6 to 12 o'clock, proceeding medially until the fibrous annulus was exposed and detached. The posterior skin of the EAC was elevated intact and, if possible, in continuity with the annulus and the pars tensa. The posterior mesotympanum was exposed. A CWD mastoidectomy was performed (Fig. 1). The cavity was always saucerised, the posterior wall of the EAC was lowered and the bony overhangs were removed in order to obtain a round-shaped cavity. The mastoid tip was usually preserved (Fig. 2). Accordingly, it was not necessary to expose the mastoid tract of the facial nerve apart from in the case of invasive cholesteatoma of the posterior mesotympanum, with deep erosion of the tympanic sinus. The matrix of the cholesteatoma located in the mastoid was completely removed (Fig. 3) unless a lateral semicircular canal fistula

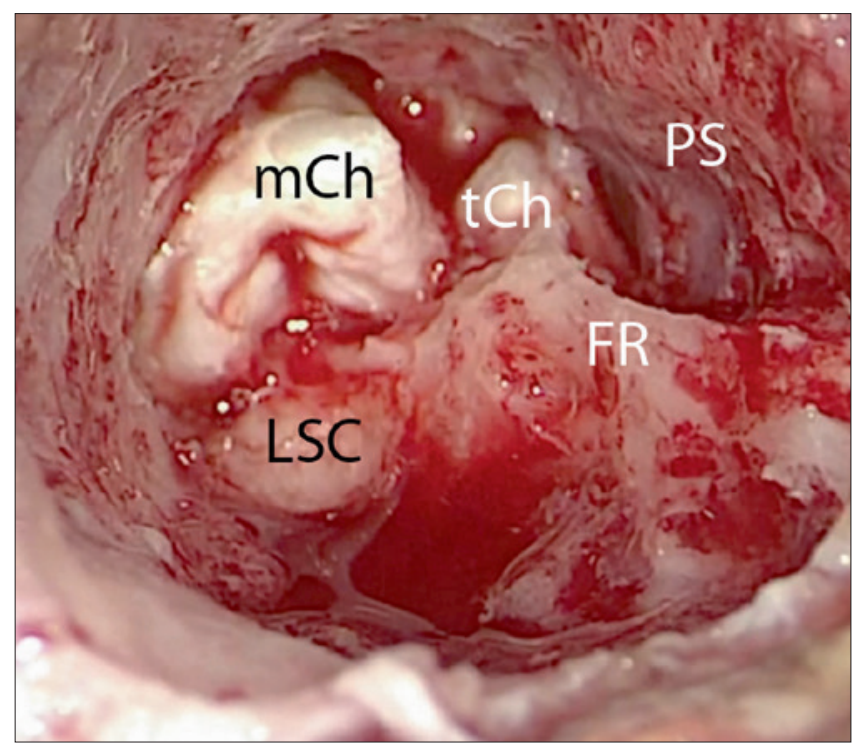

Fig. 1. A canal wall down (CWD) mastoidectomy. The lateral semicircular canal is evident (LSC) and a large amount of bone has been preserved over the mastoid segment of the facial nerve, the so-called facial ridge (FR). The cholesteatoma extends into the mastoid ( $\mathrm{mCh}$ ) and into the tympanic cavity (tCh). The skin of the postero-supero-inferior walls of the external auditory canal (PS) has been preserved. 


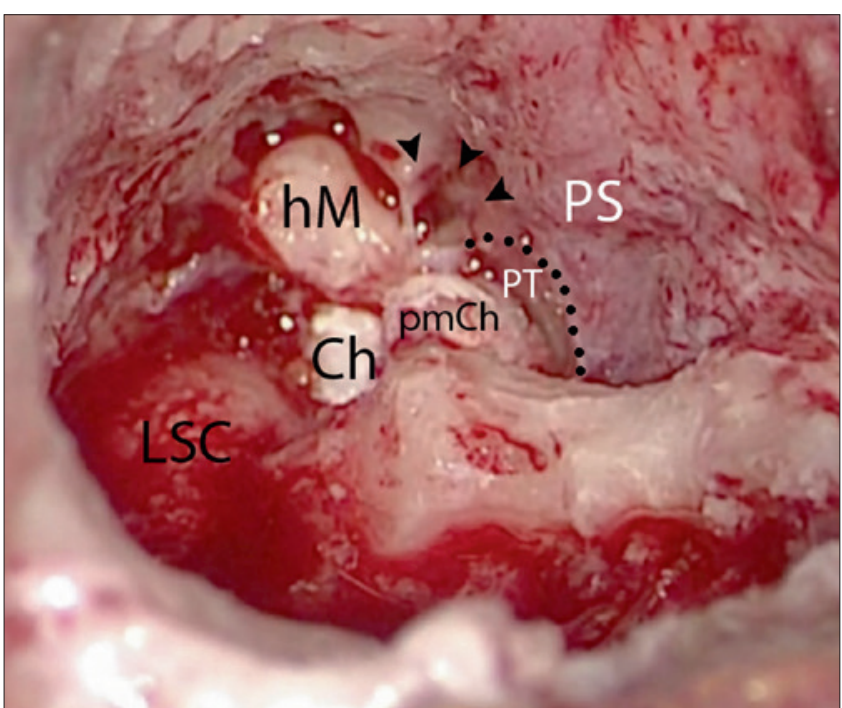

Fig. 2. Picture after the removal of the mastoid part of the cholesteatoma. The incus was completely eroded and the head of the mallus (hM) was present into the epitympanum. The cholesteatoma (Ch) extends medially to the ossicular chain and moves downward into the posterior mesotympanus (pmCh), thus eroding the stapes and infiltrating the posterior recesses. The pars tensa (PT) and the fibrous annulus (black dotted line) have been preserved and were not involved by the cholesteatoma; the lateral semicircular canal (LSC) is indicated.

was evident. In this case, the matrix was removed only if the endostium of the canal is preserved; contrariwise a layer of matrix was preserved to protect the labyrinth. A complete atticotomy was performed. The incus and the head of the malleus were removed in order to completely expose the anterior and medial epitympanum. The tendon of the malleus was sharply cut to lateralise and preserve the pars tensa of the tympanic membrane and to explore the anterior mesotympanum. The ossicular chain was left intact in rare cases where the cholesteatoma was located only in the lateral epitympanum. At the end of the procedure, the result was a round cavity with the entire tympano-mastoid compartments well exteriorised and well evident postoperatively. The cavity was mostly covered with an enlarged pedicled tympano-meatal skin flap. This flap, formed by the superior-posterior-inferior skin of the EAC, was mobilised through two incisions: a transversal incision at the level of the concha from 6 o'clock to 12 o'clock and a second longitudinal incision at 12 o'clock from the previous incision as far as the remaining pars tensa (Figs. 4, 5). The thick and vascularised tympano-meatal skin flap was positioned over the cavity to promote healing and reduce the volume of the cavity. Thus, it prevented tissue granulation and otorrhoea, and accumulation of debris.

A meatoplasty was performed in all cases.

The perforations of the pars tensa were reconstructed preferably with the temporalis fascia underlay technique.

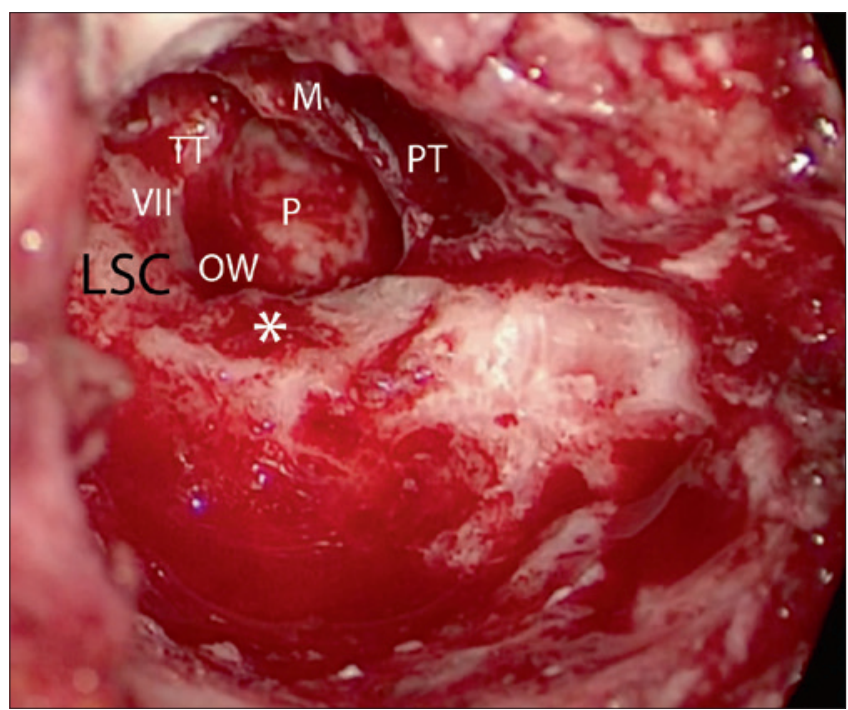

Fig. 3. The cavity after the complete removal of the cholesteatoma. After the facial ridge has been drilled $\left({ }^{*}\right)$ also the posterior mesotympanic recesses have been cleaned. The oval window (OW) is explored and the superstructure of the stapes has been eroded by the cholesteatoma. The tympanic part of the facial nerve (VII), the lateral semicircular canal (LSC), the pars tensa (PT), the handle of the malleus (M) and the tensor tympani (TT) are indicated.

The ossiculoplasty was performed with the remodeled autologous incus or with an alloplastic prosthesis if the incus was eroded.

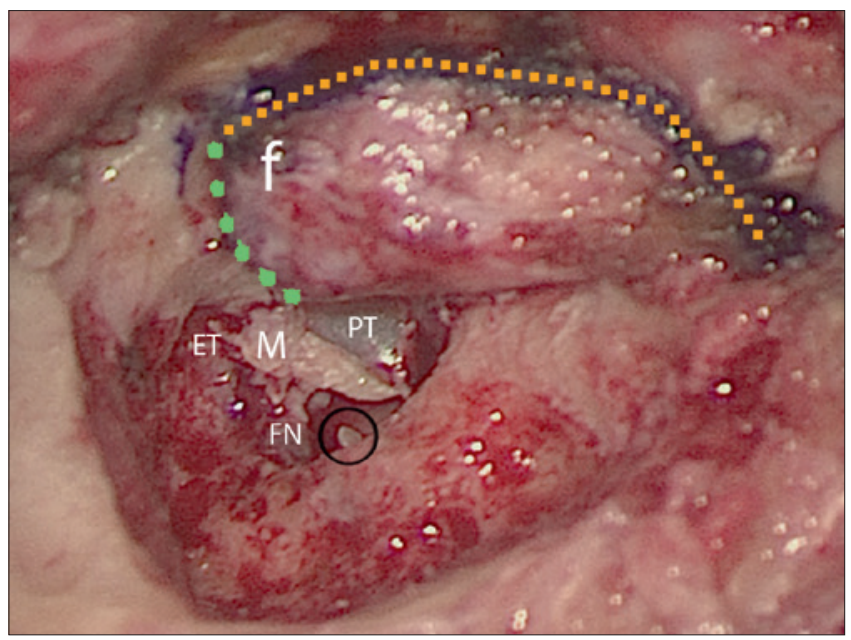

Fig. 4. The cavity after the complete removal of the cholesteatoma. The pars tensa (PT) has been removed in its posterior part. The epitympanum (ET) has been exposed after the resection of the incus and the head of the malleus. The flap ( $\mathrm{f})$, composed by the postero-supero-inferior skin of the external auditory canal, will be harvested with two incisions: a transversal incision (orange small-dotted line) at the level of the concha from 6 o'clock to $120^{\prime}$ 'clock and a second longitudinal incision at 12 o'clock from the previous incision until the remaining pars tensa (green big-dotted line). The stapes super structure was intact (black circle) FN: facial nerve; M: malleus. 


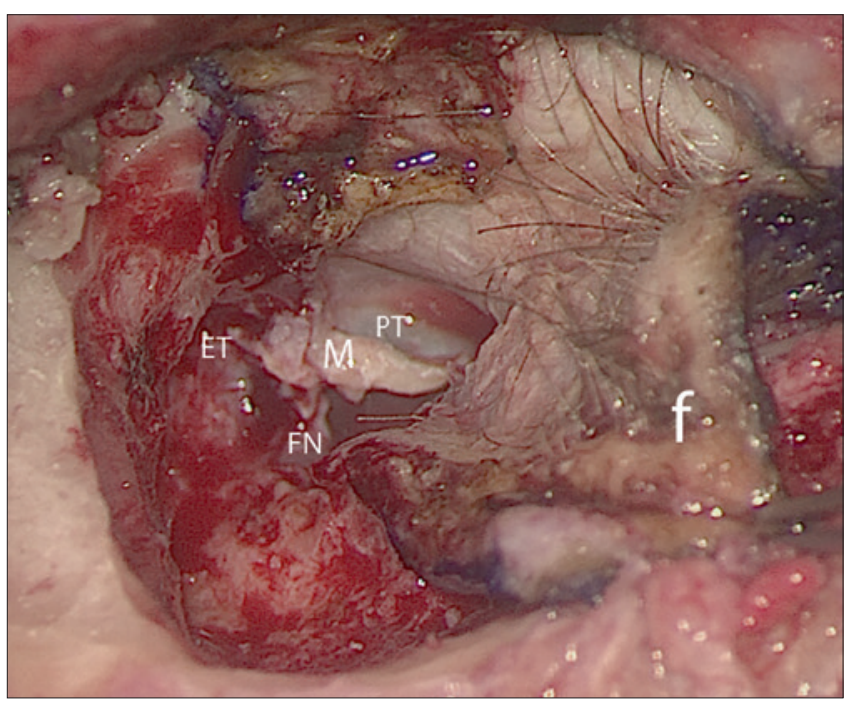

Fig. 5. The tympano-meatal pedicled skin flap $(f)$ is harvested and positioned to cover the cavity. M: malleus, ET: epitimpanum, PT: part tensa, FN: facial nerve.

\section{Results}

Between January 1992 and March 2016, 1445 patients were treated for tympano-mastoid cholesteatoma at the Otolaryngology Department of the Ospedale di Legnano (Milan, Italy). According to the inclusion criteria, 895 patients were enrolled in this survey.

All of the patients were treated with CWD mastoidectomy. Single stage surgery was performed in 673 patients (75.2\%), whereas two-stage surgery was performed in 222 cases $(24.8 \%)$. There were no major complications such as facial nerve palsy, central nervous system complication (fistula, infection, or haemorrhage), or cophosis. Of 895 patients, a revision CWD tympanoplasty for chronic otorrhea was performed in 14 cases $(1.5 \%)$ with a complete recovery in all cases. Nine of those patients had a recurrence of cholesteatoma and five had cavity problems related to granulation, de-epithelisation, or recurrent infection.

In total, 591 patients had a normal or slightly pathological middle ear mucosa and pars tensa and were included in group A, while 304 patients were classified into group
B. In group A, 225 patients $(38.1 \%)$ were adult and 366 $(61.9 \%)$ were paediatric whereas in group B, there were 207 (68.1\%) adult and 97 (31.9\%) paediatric patients.

Recidivism of disease was reported in 69 patients $(7.7 \%)$ with between 10 and 24 years of follow-up. There was persistence of disease in 60 cases $(6.7 \%)$; in 52 cases, disease was located in the posterior mesotympanum, in 5 cases in the anterior mesotympanum, and in 3 cases, in the hypotympanum. Recurrent disease occurred in 9 patients (1\%). A significant difference was evident between the rates of recidivism, residual and recurrent cholesteatoma between group A $(5.4 \%, 4.9 \%$ and $0.5 \%$, respectively) and group B $(12.2 \%, 10.2 \%$ and $2.0 \%$, respectively) (Table I).

There were no significant differences in recidivism, persistence, or recurrence according to the extent of the cholesteatoma.

Recidivism was significantly lower in adults compared to paediatric patients $(5 \%$ and $10.1 \%$, respectively, $\mathrm{p}<0.05)$ and similar results were obtained for residual disease (4.6\% and $8.6 \%$, respectively, $\mathrm{p}<0.05)$. Concerning recurrences, a difference between adult and paediatric patients was still present $(0.4 \%$ and $1.5 \%$, respectively, $\mathrm{p}=0.120$ ) that was not statistically significant. This is probably related to the low rate of recurrent disease obtained with the open approach (Table II).

Considering the long-term hearing outcomes, $36.4 \%$ of all patients had useful ear function with pure-tone average air conduction thresholds $(\mathrm{aPTA}) \leq 30 \mathrm{~dB}$ at 500 , 1000, 2000 and $4000 \mathrm{~Hz}$. Concerning group A, the stapes superstructure was present in 443 cases $(75.0 \%)$ and in this subgroup, aPTA was $\leq 30 \mathrm{~dB}$ in $60.3 \%$ of adults and $40.2 \%$ of paediatric patients. When the stapes superstructure was absent, long-term auditory outcomes deteriorated in $43.3 \%$ of adult patients and $30.2 \%$ of paediatric patients reporting aPTA $\leq 30 \mathrm{~dB}$. Postoperatively, in group A, the tympanic membrane was atelectasic in $79.5 \%$ of the children and $32.3 \%$ of the adults, which could be related to the poorer hearing results in children.

Table I. Distribution of the enrolled patients into group A and B according to age and recidivism rate (residual and recurrent cholesteatoma).

\begin{tabular}{|c|c|c|c|c|}
\hline & Total & Group A & Group B & Univariate \\
\hline Patients enrolled & $895(100 \%)$ & $591(66.0 \%)$ & 304 (34.0\%) & \\
\hline Adults & $432(48.3 \%)$ & 225 (38.1\%) & 207 (68.1\%) & \\
\hline Paediatrics & $463(51.7 \%)$ & $366(61.9 \%)$ & $97(38.9 \%)$ & $<0.05$ \\
\hline Recidivism & $69(7.7 \%)$ & $31(5.4 \%)$ & $37(12.2 \%)$ & $<0.05$ \\
\hline Residual cholesteatoma & $60(6.7 \%)$ & $29(4.9 \%)$ & $31(10.2 \%)$ & $<0.05$ \\
\hline Recurrent cholesteatoma & $9(1.0 \%)$ & $3(0.5 \%)$ & $6(2.0 \%)$ & $<0.05$ \\
\hline
\end{tabular}


Table II. Analysis of recidivism, residual and recurrent cholesteatoma according to age.

\begin{tabular}{lcccc} 
& Total & Adult (\%) & Paediatric (\%) & Univariate \\
Recidivism & 69 & $22 / 432(5.0)$ & $47 / 463(10.1)$ & $<0.05$ \\
Residual cholesteatoma & 60 & $20 / 432(4.6)$ & $40 / 463(8.6)$ & $<0.05$ \\
Recurrent cholesteatoma & 9 & $2 / 432(0.4)$ & $7 / 463(1.5)$ & 0.120 \\
\hline
\end{tabular}

Group B showed impaired hearing results with $40.2 \%$ and $30.2 \%$ of patients with aPTA $\leq 30 \mathrm{~dB}$ when the stapes superstructure was, respectively, present or absent. The presence of the stapes superstructure was associated with a significant improvement in hearing in group A, whereas in group B the pathological condition of the mucosa of the middle ear or the pathology of the tympanic membrane was related to poorer hearing results, and the absence of the stapes superstructure was associated with poorer outcomes even though the difference was not statistically significant (Table III).

A longer follow-up was associated with worsening of hearing outcomes. Six-month results were always better than the long term results in group A. Patients in group $\mathrm{B}$ with the stapes also showed significant deterioration of hearing outcomes over time, whereas in patients in group B without stapes, hearing results deteriorated over time even though there were no significant differences between the 6-month and longer term results. These data are detailed in Table III.

\section{Discussion}

The canal wall up (CWU) versus the canal wall down (CWD) approach has been extensively debated during the last few decades and controversies still exist. The goal of the present paper was not to revisit this discussion, but rather to report on long-term outcomes and prognostic factors of the CWD approach for tympano-mastoid cholesteatoma in a large and homogenous cohort of patients. Regardless of the approach, the goals of cholesteatoma surgery are to: eradicate the disease reducing the rate of recidivism, preserve or restore hearing and create a dry ear. In our hands, the CWD approach is an effective approach, achieving the goals of cholesteatoma treatment, with single-stage surgery in more than $75 \%$ of cases and without contraindications.

Table III. Functional results. S+ presence of the stapes; S- absence of the stapes.

\begin{tabular}{|c|c|c|c|c|}
\hline & TOT & $\mathrm{PTA} \leq 30 \mathrm{~dB}$ & PTA > 30dB & Univariate \\
\hline Total & 895 & $326(36.4 \%)$ & $569(63.6 \%)$ & \\
\hline Group A & 591 & $246(41.6 \%)$ & 345 (58.4\%) & \\
\hline Group B & 304 & $80(26.3 \%)$ & 224 (73.7\%) & $<0.05$ \\
\hline \multicolumn{5}{|l|}{ Group A } \\
\hline Adults & 225 & 118 (52.4\%) & 107 (47.6\%) & \\
\hline Paediatrics & 366 & 128 (35.0\%) & $238(65.0)$ & $<0.05$ \\
\hline Adults S+ & 121 & $73(60.3 \%)$ & 48 (39.7\%) & \\
\hline Adults S- & 104 & $45(43.3 \%)$ & 59 (56.7\%) & $<0.05$ \\
\hline Paediatrics S+ & 174 & $70(40.2 \%)$ & 104 (59.8\%) & \\
\hline Paediatrics S- & 192 & $58(30.2 \%)$ & $134(69.8 \%)$ & $<0.05$ \\
\hline $\mathrm{S}+(6$ months $)$ & 295 & 234 (79.3\%) & $61(20.7 \%)$ & \\
\hline S+ & 295 & 143 (48.5\%) & 152 (51.5\%) & $<0.05$ \\
\hline S- (6 months) & 296 & 163 (55.1\%) & 133 (44.9\%) & \\
\hline S- & 296 & 103 (34.8\%) & $193(65.2 \%)$ & $<0.05$ \\
\hline \multicolumn{5}{|l|}{ GROUP B } \\
\hline S+ & 207 & $610(29.5 \%)$ & $146(70.5 \%)$ & \\
\hline S- & 97 & 19 (19.5\%) & 78 (80.5\%) & .07 \\
\hline S+ (6 months) & 207 & 93 (44.9\%) & 114 (55.1\%) & $<0.05^{\star}$ \\
\hline S- (6 months) & 97 & $29(29.9 \%)$ & $68(70.1 \%)$ & $0.096^{\star \star}<0.05^{\star \star \star}$ \\
\hline
\end{tabular}

${ }^{*}$ Comparison of the results at 6 months of follow up with the long term results in patients with the stapes in the group $B .{ }^{* *}$ Comparison of the results at 6 months of follow up with the long term results in patients without the stapes in the group $B .{ }^{\star \star *}$ Comparison of the results at 6 months of follow up between patients with and without stapes in the group $B$. 
In this study, the recidivism rate for the CWD approach was $7.7 \%$, which is comparable to the $2-18 \%$ reported in the literature ${ }^{267}$. Two different kinds of recidivism must be considered. Residual cholesteatoma is defined as nonradically removed epidermoid cells ${ }^{8}$, whereas a recurrence is a new retraction pocket containing keratin that has evolved into a cholesteatoma ${ }^{9}$. The CWD approach has been demonstrated to minimise the rates of both residual and recurrent disease ${ }^{10}{ }^{11}$. The wide exposure created by the CWD technique guarantees the complete removal of the matrix from the mastoid, the epitympanum and from the recesses of the tympanic cavity, thus reducing the rates of residual cholesteatoma. Residual cholesteatoma rates were estimated at between $0 \%$ and $7 \%{ }^{(8)}$ in a recent review. In our analysis, residual cholesteatoma was evident in $6.7 \%$ of cases and was mainly located in the posterior mesotympanum, the most common site of persistence ${ }^{12}$. Most of the recurrences after a CWD approach should be considered to be technical errors; their incidence is estimated in the literature at between 0 and $15 \%{ }^{8}$, and in our hands affected $1 \%$ of cases. The two principal causes of recurrence in the CWD approach are insufficient lowering of the facial ridge and inadequate meatoplasty ${ }^{13}$. The lowering of the facial ridge reduces the volume of the middle ear thus avoiding the creation of retraction pockets. In fact, in the case of tube dysfunction, the tympanic membrane will become atelectasic instead of creating pockets. Furthermore, a round cavity with smooth margins with adequate meatoplasty will provide a dry and self-cleaning cavity. The CWU approach presents a recidivism rate that is 2.87 times higher, ranging between $9 \%$ and $70 \%{ }^{4}$. It preserves both the normal anatomy of the ear canal and the normal volume of the middle ear, but is commonly accepted to have limited surgical exposure ${ }^{14}$ thus leading to an increased rate of persistence, ranging between $3.1 \%$ and $20 \%{ }^{8}$. Neither second surgery nor adequate follow-up are able to reduce the rate of evolving retraction pockets after a CWU approach ${ }^{19}{ }^{20}$. These are related to the persistence of a large air-filled cavity behind the tympanic membrane and the posterior canal wall together with the intratympanic negative pressure. In such cases, the surgery proposed is usually a CWD approach, in order to avoid further failures due to recurrence of retraction pockets.

The prognostic factors for recidivism after a CWD approach are pathological condition of the tympanic membrane and middle ear mucosa, age of the patient and length of follow-up.

Extent of disease was not a prognostic factor because the open approach always gives the possibility to ex- pose and remove the cholesteatoma from the mastoid and middle ear ${ }^{(15)}$ and, during follow-up, to identify and remove pearls in the mastoid cavity or epitympanum; these pearls were not deemed to be persistent ${ }^{16}$ because their removal under local anaesthesia is part of regular follow-up. Thus, the mesotympanum, and rarely the hypotympanum, are the only sites at risk for persistence, in particular, when the presence of pathological middle ear mucosa and atelectasic or perforated pars tensa makes it difficult to identify and remove the cholesteatoma completely 101324 . As demonstrated by our results, group B reported more than double the rate of recidivism, recurrence and persistence than group A.

The rate of cholesteatoma recidivism in children was higher than in adults $(5.0 \%$ versus $10.1 \%$, respectively, $\mathrm{p}<0.05$ ). Most otologists have assumed that cholesteatoma in children is more aggressive than in adults and tends to form bud-like extensions into surrounding tissues making total removal of the disease difficult ${ }^{15} 17$.

The length of follow-up is a well-recognised prognostic factor for both anatomical and functional results ${ }^{15}$. When reporting results after cholesteatoma surgery, an adequate follow-up period is required considering that cholesteatoma recurrences can develop even after 12 years of follow-up ${ }^{18}$. Consequently, in our study, a minimum of 10 years of follow-up was considered adequate for reporting definitive anatomical and functional results, and only a few papers in the literature have presented such long-term results.

Concerning functional outcomes, there are different opinions concerning the different approaches and techniques. According to several papers ${ }^{19-22}$, the CWD approach is related to a poorer hearing outcome compared to the CWU approach because of the anatomical alteration of the external and middle ear and the increased risk of adhesion and fibrosis of the prosthesis to the promontory or to the facial nerve. On the other hand, several studies reported similar functional results between the open and closed approaches 610112324 . In this regard, the end point adopted and the length of follow-up dramatically influence the functional results. The most frequently used end point in the literature is the air-bone gap $(A B G)$, but gives no information on the real hearing status. The end point we adopted was the pure-tone average air conduction threshold (aPTA) after 6 months and after more than 10 years. We considered hearing to be serviceable when the aPTA was lower than $30 \mathrm{~dB}$, and the frequencies evaluated were $500 \mathrm{~Hz}, 1000 \mathrm{~Hz}, 2000$ $\mathrm{Hz}$ and $4000 \mathrm{~Hz}$ in order to completely analyse the range of the speaking human voice. In particular, we included $4000 \mathrm{~Hz}$ because this frequency region is often damaged 
by chronic otitis ${ }^{25}{ }^{26}$ and is the most challenging to recover with ossiculoplasty ${ }^{27}$; the choice of this end point could be related to deterioration of the results.

The other important factor is length of follow-up. The healing process takes several years and leads to a progressive deterioration of hearing, as shown by our results where 6-month functional outcomes were significantly better than the long-term results.

In our analysis, $36.4 \%$ of all patients enrolled reported an aPTA lower than $30 \mathrm{~dB}$. The results in the literature are similar to the data reported in our study. Vartiainen ${ }^{(17)}$ reported a postoperative PTA lower than $40 \mathrm{~dB}$ in $38.8 \%$ of patients treated with a CWD approach for cholesteatoma after 10 years, but the author does not account for the $4000 \mathrm{~Hz}$ region. Other authors reported a mean postoperative PTA ranging from 31.2 to $42.4 \mathrm{~dB}^{228}{ }^{29}$, but with a follow-up shorter than 5 years and the $4000 \mathrm{~Hz}$ region was not always included.

According to our data, the preoperative factors that influence the functional results are: pathological factors (mucosa of the middle ear and/or pathological condition of the pars tensa of the tympanic membrane), anatomical factors (presence of the stapes superstructure), age of patients and length of follow-up. The presence of pathological middle ear mucosa and atelectasic or perforated pars tensa was associated with a deterioration of the long-term hearing outcomes. In our analysis, $41.6 \%$ of patients in group A reported serviceable hearing, which was significantly better than the $26.3 \%$ reported in group B. Similar results are reported in the literature 21920 30-32. The role of the stapes superstructure has been widely discussed in the literature with contrasting results. Some authors pointed out the importance of the handle of the malleus ${ }^{12040}$ speculating that the stapes superstructure promotes postoperative fibrosis and adhesion leading to poorer hearing outcomes. On the other hand, several studies have reported that the presence of the stapes suprastructure is a positive predicting factor for functional outcome ${ }^{33-35}$. Supporting this statement, our long-term data for group A showed that adults with the stapes superstructure reported an aPTA $<30 \mathrm{~dB}$ in $60.3 \%$ of cases compared with $43.3 \%$ without the stapes superstructure $(\mathrm{p}<0.05)$. Similar results were reported in group $\mathrm{B}$, but without reaching a significant difference. Paediatric patients reported poorer hearing outcomes probably related to the increased rate of postoperative atelectasis of the tympanic membrane $(79.5 \%$ vs $32.3 \%$ in the adults in group A). Once the tympanic membrane has become atelectasic, there is little or no chance to reconstruct an air-filled middle ear cavity. Thus, the most important factor for a serviceable hearing function in these patients is the presence of a monolateral lesion.
The major advantage of the CWU approach is the creation of a dry ear postoperatively ${ }^{436}$, whereas the CWD approach has been associated with prolonged healing, debris accumulation, chronic otorrhea, water intolerance and vertigo. In the literature, the incidence of infection of the cavity and/or chronic otorrhoea is estimated to be as high as $33 \%{ }^{37}$ with the CWD approach. In the vast majority of cases, these results are probably related to technical errors such as a high facial ridge, irregular cavity, or a stenotic meatotomy since a correctly performed CWD approach has been demonstrated to achieve a dry and water tolerant ear in more than $95 \%$ of cases ${ }^{9}$. In agreement with this, in the present paper, otorrhoea was evident in 14 patients $(1.5 \%)$. The cause of otorrhoea was a recurrence in 9 patients, whereas five patients underwent revision surgery for cavity problems (recurrent infections, granulations, or stenotic meatotomy).

\section{Conclusions}

This retrospective study on a large and uniform cohort of patients showed that the CWD approach is a cornerstone in the management of tympano-mastoid cholesteatoma. The open approach was associated with a very low rate of recidivism (7.7\%) after a follow-up between 10 and 24 years. Recurrences of cholesteatoma were related to technical errors and, theoretically, should be absent if the surgery was performed strictly according to the principles of the CWD technique. Residual diseases were located in the mesotympanum and hypotympanum since the epitympanum and mastoid cavity were exteriorised by the surgical procedure and examined during regular followup. The prognostic factors associated with an increased rate of recidivism for the open approach were the pathological condition of the mucosa of the middle ear and the pars tensa, paediatric age and length of follow-up. The extent of the cholesteatoma was not a prognostic factor. The long-term functional results were unsatisfactory since only $36.4 \%$ of all of patients reported an aPTA $\leq 30$ $\mathrm{dB}$. Long-term follow-up was associated with a deterioration of hearing. The pathological condition of the mucosa of the middle ear and pars tensa was the main negative prognostic factor. The presence of stapes was associated with better functional outcomes. Paediatric patients were associated with poorer hearing, and this could be related to the increased rate of postoperative atelectasis reported in this group.

\section{Conflict of interest statement}

None declared. 


\section{References}

1 Yung M, Tono T, Olszewska E, et al. EAONO/JOS Joint Consensus Statements on the definitions, classification and staging of middle ear cholesteatoma. J Int Adv Otol 2017;3:1-8.

2 Aslan Felek S, Islam A, Celik H, et al. The functional and anatomical results of the canal wall down tympanoplasty in extensive cholesteatoma. Acta Otolaryngol 2009;129:1388-94.

3 Nikolopoulos TP, Gerbesiotis P. Surgical management of cholesteatoma: the two main options and the third way-atticotomy/limited mastoidectomy. Int J Pediatr Otorhinolaryngol 2009;73:1222-7.

4 Tomlin J, Chang D, McCutcheon B, et al. Surgical technique and recurrence in cholesteatoma: a meta-analysis. Audiol Neurootol 2013;18:135-42.

5 Nyrop M, Bonding P. Extensive cholesteatoma: long-term results of three surgical techniques. J Laryngol Otol 1997;111:521-6.

6 Ajalloueyan M. Experience with surgical management of cholesteatomas. Arch Otolaryngol Head Neck Surg 2006;132:931-3.

7 Cho YS, Hong SD, Chung KW, et al. Revision surgery for chronic otitis media: characteristics and outcomes in comparison with primary surgery. Auris Nasus Larynx 2010;37:18-22.

8 Kerckhoffs KG, Kommer MB, van Strien TH, et al. The disease recurrence rate after the canal wall up or canal wall down technique in adults. Laryngoscope 2016;126:980-7.

9 Kos MI, Castrillon R, Montandon P, et al. Anatomic and functional long-term results of canal wall-down mastoidectomy. Ann Otol Rhinol Laryngol 2004;113:872-6.

10 Roden D, Honrubia VF, Wiet R. Outcome of residual cholesteatoma and hearing in mastoid surgery. J Otolaryngol 1996;25:178-81.

11 Declerck T. Resultaten na cholesteatoomchirurgie: Een retrospectieve analyse. Master in de Geneeskunde, Gent Universiteit (Be). 05/05/2010.

12 Smyth GD. Cholesteatoma surgery: the influence of the canal wall. Laryngoscope 1985;95:92-6.

13 Bhatia S, Karmarkar S, DeDonato G, et al. Canal wall down mastoidectomy: causes of failure, pitfalls and their management. J Laryngol Otol 1995;109:583-9.

14 Hulka GF, McElveen JT, Jr. A randomized, blinded study of canal wall up versus canal wall down mastoidectomy determining the differences in viewing middle ear anatomy and pathology. Am J Otol 1998;19:574-8.

15 Britze A, Moller ML, Ovesen T. Incidence, 10-year recidivism rate and prognostic factors for cholesteatoma. J Laryngol Otol 2017;131:319-28.

16 de Zinis LO, Tonni D, Barezzani MG. Single-stage canal wall-down tympanoplasty: long-term results and prognostic factors. Ann Otol Rhinol Laryngol 2010;119:304-12.

17 Vartiainen E. Ten-year results of canal wall down mastoidectomy for acquired cholesteatoma. Auris Nasus Larynx 2000;27:227-9.

18 Vartiainen E. Factors associated with recurrence of cholesteatoma. J Laryngol Otol 1995;109:590-2.
19 Albu S, Babighian G, Trabalzini F. Prognostic factors in tympanoplasty. Am J Otol 1998;19:136-40.

20 Dornhoffer JL, Gardner E. Prognostic factors in ossiculoplasty: a statistical staging system. Otol Neurotol 2001;22:299-304.

21 Schraff SA, Strasnick B. Pediatric cholesteatoma: a retrospective review. Int J Pediatr Otorhinolaryngol 2006;70:385-93.

22 Shirazi MA, Muzaffar K, Leonetti JP, et al. Surgical treatment of pediatric cholesteatomas. Laryngoscope 2006;116:1603-7.

23 Gocmen H, Kilic R, Ozdek A, et al. Surgical treatment of cholesteatoma in children. Int J Pediatr Otorhinolaryngol 2003;67:867-72.

$24 \mathrm{Kim} \mathrm{MB}$, Choi J, Lee JK, et al. Hearing outcomes according to the types of mastoidectomy: a comparison between canal wall up and canal wall down mastoidectomy. Clin Exp Otorhinolaryngol 2010;3:203-6.

25 Carrillo RJ, Yang NW, Abes GT. Probabilities of ossicular discontinuity in chronic suppurative otitis media using pure-tone audiometry. Otol Neurotol 2007;28:1034-7.

26 Amali A, Hosseinzadeh N, Samadi S, et al. Sensorineural hearing loss in patients with chronic suppurative otitis media: is there a significant correlation? Electron Physician 2017;9:3823-7.

27 Sevik Elicora S, Erdem D, Dinc AE, et al. The effects of surgery type and different ossiculoplasty materials on the hearing results in cholesteatoma surgery. Eur Arch Otorhinolaryngol 2017;274:773-80.

28 Umit T, Ozgur Y, Bilgehan G, et al. Results of primary ossiculoplasty and prognostic factors in canal wall-down tympanoplasty. $\mathrm{J}$ Craniofac Surg 2010;21:407-10.

29 Goyal R, Mourya A, Qureshi S, et al. Modified radical mastoidectomy with type III tympanoplasty: revisited. Indian J Otolaryngol Head Neck Surg 2016;68:52-5.

30 Vartiainen E, Nuutinen J. Long-term results of surgical treatment in different cholesteatoma types. Am J Otol 1993;14:507-11.

31 Black B. Reporting results in ossiculoplasty. Otol Neurotol 2003;24:534-42.

32 Silverstein H, McDaniel AB, Lichtenstein R. A comparison of PORP, TORP, and incus homograft for ossicular reconstruction in chronic ear surgery. Laryngoscope 1986;96:159-65.

33 Bared A, Angeli SI. Malleus handle: determinant of success in ossiculoplasty. Am J Otolaryngol 2010;31:235-40.

34 Mardassi A, Deveze A, Sanjuan M, et al. Titanium ossicular chain replacement prostheses: prognostic factors and preliminary functional results. Eur Ann Otorhinolaryngol Head Neck Dis 2011;128:53-8.

35 Wilson KF, Hoggan RN, Shelton C. Tympanoplasty with intact canal wall mastoidectomy for cholesteatoma: long-term surgical outcomes. Otolaryngol Head Neck Surg 2013;149:292-5.

36 Dodson EE, Hashisaki GT, Hobgood TC, et al. Intact canal wall mastoidectomy with tympanoplasty for cholesteatoma in children. Laryngoscope 1998;108:977-83.

37 Goldenberg RA. Sink-trap effect as a cause of failure in mastoidectomy. Laryngoscope 1988;98:1143-4.

Received: June 18, 2018 - Accepted: November 19, 2018

How to cite this article: Pareschi R, Lepera D, Nucci R. Canal wall down approach for tympano-mastoid cholesteatoma: long-term results and prognostic factors. Acta Otorhinolaryngol Ital 2019;39:122-129. https://doi.org/10.14639/0392-100X-2237

Address for correspondence: Davide Lepera, Department of Otorhinolaryngology, Ospedale Nuovo di Legnano, via Papa Giovanni Paolo II, 20025 Milano, Italy. Tel. +39 0331 449707. E-mail: davide.lepera86@gmail.com 